\title{
Factors affecting modern contraceptive use among fecund young women in Bangladesh: does couples' joint participation in household decision making matter?
}

Ahmed Zohirul Islam(i)

\begin{abstract}
Objectives: The purpose of the study was to explore the association between couples' joint participation in household decision making and modern contraceptive use (MCU) among fecund (physically able to bear child) young women in Bangladesh.

Methods: This study utilized a cross-sectional data $(n=3507)$ extracted from the Bangladesh Demographic and Health Survey (BDHS) 2011. Differences in the utilization of modern contraceptives (MC) by socio-demographic characteristics were assessed by $x^{2}$ analyses. Binary logistic regression was used to identify the associated factors of usingMC, and the odds ratio with a $95 \% \mathrm{Cl}$ was computed to assess the strength of association. Multicollinearity was also checked by examining the standard errors in the fitted model.

Results: Desire for a child after two years go by and no child at all contributed the most to increasing MCU followed by receiving family planning (FP) methods from FP workers. Couples' joint decision making power on women's health care, child's health care and visiting family members or relatives emerged as the third most influential factor that might be associated with MCU.

Conclusions: Since spousal joint decision making increases the likelihood of using MC, government should include strategic interventions in FP programs to elevate women's status through creating educational and employment opportunities and encouraging more visible involvement in household decision making.
\end{abstract}

Keywords: Decision making power, women's empowerment, Young women, Modern contraceptives, Family planning, BDHS

\section{Plain English summary}

This study aimed to explore the association between couples' joint participation in household decision making and modern contraceptive use (MCU) among young women in Bangladesh. Present study utilized a cross-sectional data extracted from the Bangladesh Demographic and Health Survey 2011. A total of 3507 currently married women below 25 years old from total

Correspondence: zohirul.18@gmail.com

Department of Population Science and Human Resource Development,

University of Rajshahi, Rajshahi 6205, Bangladesh surveyed 17,842 women aged 15-49 years were selected for analyses.

The highest increase of the likelihood of using modern contraceptives (MC) was found among young women who desired a child after two years go by or no child at all, followed by those who were given family planning (FP) methods by FP workers. Remarkably, couples' joint participation in decision making on women's health care, child's health care and visiting family members or relatives emerged as the third most influential factor that might increase the likelihood of usingMC.

(C) The Author(s). 2018 Open Access This article is distributed under the terms of the Creative Commons Attribution 4.0 International License (http://creativecommons.org/licenses/by/4.0/), which permits unrestricted use, distribution, and 
In conclusion, government should include strategic interventions in FP programs to lift up women's status through creating educational and employment opportunities and encouraging more visible involvement in household decision making.

\section{Introduction}

Family planning (FP) is one of the major issues in many developing countries where poor maternal and child health care services are practiced $[1,2]$. Studies show that contraceptive use averts 272,040 maternal deaths by reducing the chance of pregnancy and the associated complications (exposure reduction), lowering the risk of having an unsafe abortion (vulnerability reduction), delaying first pregnancy in young women who might have premature pelvic development, and reducing hazards of frailty from high parity and closely spaced pregnancies [3] and prevents almost 230 million births every year worldwide [4]. Statistics showed that an increase of 15 to $17 \%$ of using contraceptives reduces population growth by one birth for one woman [5]. However, 62\% Bangladeshi women aged 15-49 years use some method of contraception, and 54\% use modern methods [6]. Literature shows that women's lack of power restricts their ability to make decisions about FP practice $[7,8]$. Although women's empowerment is a key to using contraceptives [9], most partners give inferior positions to women in all aspects of decision-making in developing countries [9-11]. Besides, little is known about how participation in household decision-making is associated with the utilization of modern contraceptives (MC) among young women in Bangladesh.

The population of the world became 7336 million in 2015 where South Asia contributed 1834 million people. Bangladesh, the third most populous country in South Asia comprises of 160.4 million people [12], where half of the population is aged below 25 years [13]. As this large cohort of young people enter the reproductive life span, the growth and size of the population of Bangladesh over the next few decades will largely depend on their reproductive behaviour. A considerable number of young adults get married every year. Fulfillment of their contraceptive demand is crucial to the ongoing FP programmes. Therefore, this study focuses on assessing the modern contraceptive use (MCU) status of women under 25 years old.

There is a body of literature that suggests some socio economic and demographic factors, such as residence [14], education [15, 16], age [16], economic status [17], employment status [18], religion [19, 20], parity [21], access to media [15, 19], autonomy [22, 23], desire for children [23], marital status [14] and partner communication [19], have been associated with the use ofMC. In addition, other studies revealed that women's power and autonomy is favorably related to better reproductive health and use of contraceptives [24-27]. These studies commonly provide evidence for one compelling proposition that women who exhibit substantial autonomy in the household have greater ability to control their body and achieve desired fertility. Decisions about adopting FP such as using contraceptives for either spacing or liming childbirth are often strongly shaped by spousal relationships [28]. Hence, this study attempted to address the question of whether couples' joint participation in household decision making or women's independent household decision making is more influential inMCU. Furthermore, since infecund women are physically unable to bear child and pregnant women are not currently in need of using contraceptives, including these women may bias the results. Therefore, this study aimed to address this gap in knowledge by exploring the association between couples' joint participation in household decision making and use of $\mathrm{MC}$ among currently married, fecund (physically able to bear child) and non-pregnant (who were not pregnant during the survey) young women in Bangladesh.

\section{Methods \\ Data sources}

This study used a representative set of cross-sectional data extracted from the Bangladesh Demographic and Health Survey (BDHS) 2011. The survey was conducted under the authority of the National Institute of Population Research and Training (NIPORT) of the Ministry of Health and Family Welfare, Bangladesh. Under this survey, Bangladesh was divided into seven administrative regions called divisions such as Barisal, Chittagong, Dhaka, Khulna, Rajshahi, Rangpore and Sylhet. Each division was subdivided into districts, and each district into upazilas. Each rural area in an upazila was divided into union parishads (UP) and mouzas within a UP. An urban area in the upazila was divided into wards, and into mohallas within a ward [29].

According to the official report of BDHS 2011 [29], a total of 47 people were trained to conduct household listing, to delineate Enumeration Areas (EAs), and to administer Community Questionnaires. They were also got training for the use of global positioning system (GPS) units, to obtain locational coordinates for each selected EA. The training hold out for seven days from May 1121, 2011. A household listing operation was carried out in all selected EAs from May 22 to October 5, 2011 in four phases, each about three weeks in length. Training for the main survey was lasted for four weeks from June 6 to July 5, 2011. A total of 173 fieldworkers were recruited based on their educational level, prior experience with surveys, maturity, and willingness to spend up to six months on the project. Fieldwork for the 2011 BDHS was conducted by 16 interviewing teams, each consisting of one supervisor, one field editor, five female interviewers, two male 
interviewers, and one logistics staff member. The collection of data was accomplished in five phases, starting on July 8, 2011 and ending on December 27, 2011.

A nationally representative household based sample was created through a stratified, multistage cluster sampling strategy of which 600 primary sampling units were constructed (207 in urban areas and 393 in rural areas). The primary sampling units were derived from a sampling frame created for the 2011 Population and Housing Census, provided by Bangladesh Bureau of Statistics (BBS). Detailed information on survey design and sampling procedures has been reported elsewhere [29]. A total of 17,842 ever married women aged 15-49 were interviewed in the survey. After applying the definition of young people adopted by the United Nations [30], a total of 3507 currently married non-pregnant fecund women younger than 25 years, who were in actual need of using contraceptives, were selected for analyses (Fig. 1).

\section{Response variable}

The outcome variable of this study wasMCU, which is binary in nature (use or non-use). During the survey, sexually active women were asked if they were currently using any method to delay or avoid getting pregnant.
Those that reported using any method to delay or avoid getting pregnant were further asked to indicate what they were doing or the method they were using. MC, such as pills, condoms, Intra-Uterine Devices (IUD), injections and implants/norplants, refer to safe and effective methods to prevent pregnancy [29]. A binary variable is then created and categorized as using any type of $\mathrm{MC}$ and versus no use.

\section{Statistical analyses}

This study begins with descriptive exploration of both dependent and independent variables. Differences in MCU by socio-demographic characteristics were assessed by $x^{2}$ analyses, with significance for all analyses set at $P<0.05$. Since the response variable of this study had two categories, the binary logistic regression model was fitted to assess the net effect of selected socio-demographic variables. Because stepwise logistic regression analysis is a technique for selecting influential variables in multiple regression models [31], this study used this technique of analysis (backward LR method). All the variables significant in bivariate analyses were simultaneously included in the stepwise logistic regression model, and finally, the most influential predictors

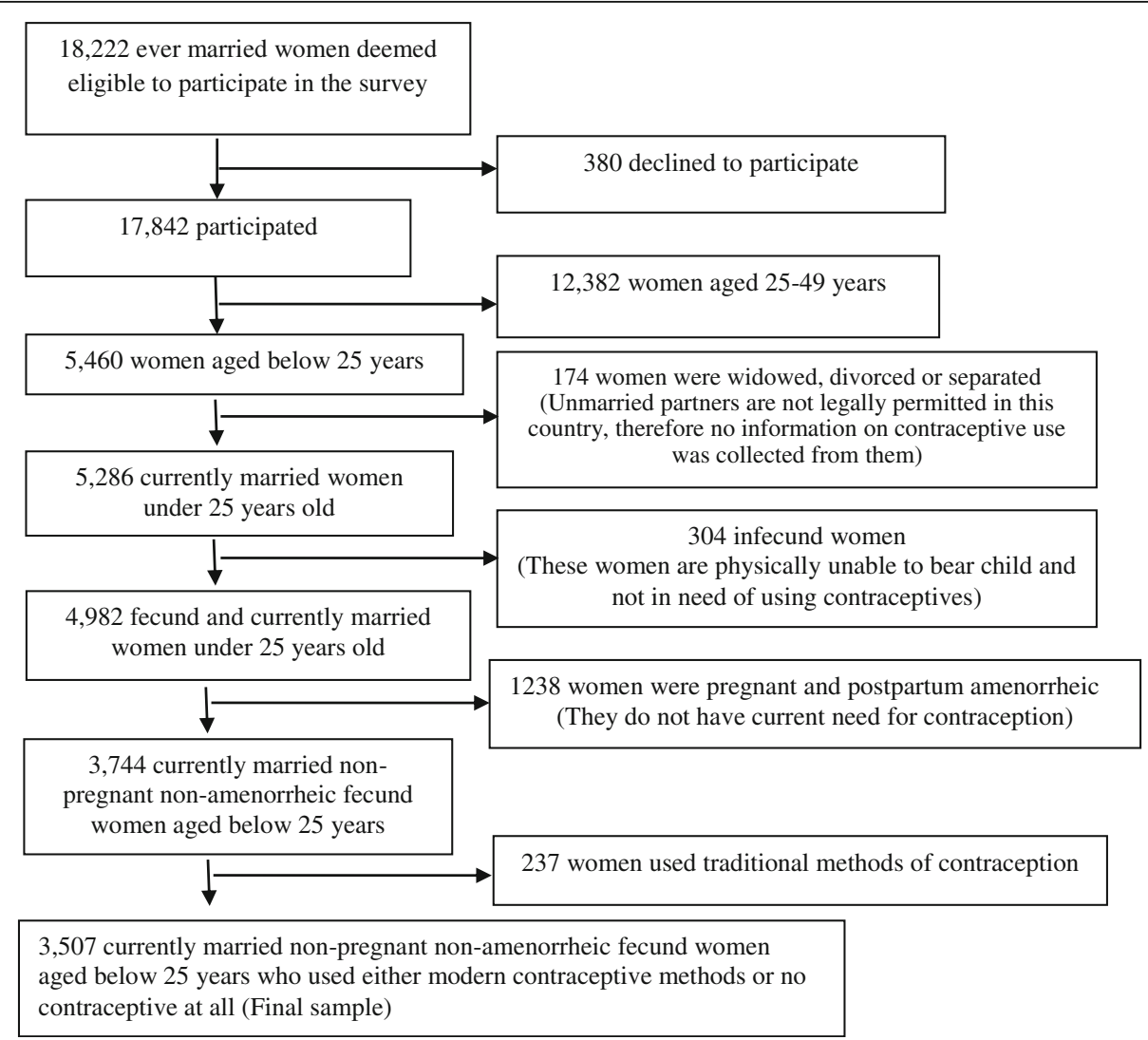

Fig. 1 From 17,842 women aged 15-49 years a total of 3507 currently married fecund non-pregnant young women were considered for analyses: BDHS 2011 
for MCU were explored. Multicollinearity in the logistic regression analyses in this study was checked by examining the standard errors for the regression coefficients. A standard error larger than 2.0 indicates numerical problems, such as multicollinearity among the independent variables [32]. All of the independent variables in the fitted model had a standard error $<0.75$ that indicate absence of multicollinearity in the study. Missing values are omitted from the analysis. Data were analyzed using SPSS Release 21.0 (SPSS Inc., Chicago, IL).

\section{Results}

Modern contraceptive use status and socio-demographic profiles

Table 1 describes the percentage distribution of using $\mathrm{MC}$ according to socio-demographic characteristics of 3507 currently married women younger than 25 years. Modern contraceptive prevalence was $69 \%$ among fecund women aged below 25 years. This study elucidates that $18 \%$ of women who wanted a child after two years go by were at risk of having mistimed pregnancies, $15 \%$ of women who wanted no child at all were at risk of encountering unwanted pregnancies in their young ages and $47 \%$ of women who were undecided about having child were at risk of getting unplanned pregnancies due to not using contraceptives.

This study also revealed several socio-demographic factors that might be associated with MCU at a bivariate level of analysis, using the chi-square test and hence, provided $p$-values for the differences of the groups within each explanatory variable according to the percentages of using versus not using MC (Table 1). MCU was found highest among fecund women aged 23-24 years, those who were non-Muslim, who got married before age of 15 years, who had two or more living children, those whose husbands were professional non-manual workers, who lived in Barisal division, who resided in the urban areas and who jointly took decision with their husbands regarding their own health care, child health care, large household purchases and visiting to family members or relatives.

\section{Factors affecting modern contraceptive use of young women}

Stepwise logistic regression analyses were performed to identify the most influential factors that might affect the likelihood of using MC. Table 2 shows that the highest increase of the likelihood of using MC was found among young women who desired a child after two years go by or no child at all, followed by those who were given FP methods by FP workers, who took decision together with their husbands about women's own healthcare, child's healthcare, and visiting family members or relatives, who had increasing number of living children, whose husbands were professional workers, and who were
non-Muslim. This study also indicated that the greatest decrease of the likelihood of using MC was observed among women who lived in Sylhet or Chittagong region, followed by women who did not know about their husbands' desires for the number of children and who lived in the rural areas of the country.

We observed that women who desired a child after two years go by were more likely to use MC [OR $(95 \%$ CI): 14.004 (10.841-18.091), $p<0.001]$ and who wanted no child at all were also more likely to use MC $\operatorname{OOR}(95 \%$ CI): 10.854 (7.517-15.674), $p<0.001]$ than who desired a child within two years go by. Besides, women who were undecided about having a child were 3.477 times and who wanted another child but unsure about timing were 5.949 times likely to use MC compared to those who wanted another child within two years go by. Women who were given FP methods by the FP workers were 5.047 [(95\% CI): $(2.151-11.840), p=<0.001]$ times likely to use $\mathrm{MC}$ than their counterparts who only talked with the FP workers.

The likelihood of using MC was increased when husband and wife jointly participate in decision making on respondent's own health care [OR (95\% CI): 2.761 (1.925-3.960), $p<0.001]$, on child health care [OR (95\% CI): 2.616 (1.808-3.786), $\mathrm{p}<0.001$ ], and on visiting family members or relatives [OR $(95 \% \mathrm{CI})$ : 1.830 (1.176-2.849), $p=0.007$ ] than their counterparts who decided alone about these issues. It was also observed that if decisions about health care of women, child health care and visiting family members or relatives were taken by husband alone then the likelihood of using MC was increased by 2.698 times, 2.164 times and 1.559 times respectively compared to the women who took decision alone about these matters.

We also observed that number of living children played a significant role in contraceptive use since the likelihood of using MC was increased [OR (95\% CI): 1.951 (1.516-2.511), $p<0.001]$ with increasing the number of children. The likelihood of using $\mathrm{MC}$ increased [OR (95\% CI): 1.701 (1.354-2.138), $p<0.001]$ among women whose husbands were professional (non-manual) workers compared to their counterparts whose husbands were manual workers. Non-Muslim women were more likely to use MC than their Muslim counterparts.

Women residing in Sylhet, Chittagong, Dhaka, and Rangpur division were $0.231,0.259,0.479$, and 0.589 times likely to use modern contraceptives than who lived in Barisal division, respectively. Women who resided in the rural areas were less likely to use [OR $(95 \% \mathrm{CI})$ : 0.617 (0.502-0.759), $p<0.001$ ] modern contraceptives than who lived in the urban areas. The likelihood of using modern contraceptives was decreased among women who did not know about their husbands' desires for having children than those women who desired equal 
Table 1 Percentage distribution of modern contraceptive use by socio-demographic characteristics of women: BDHS 2011 $(n=3507)$

\begin{tabular}{l}
\hline \\
\hline Characteristics \\
Age (years) \\
$15-19$ \\
$20-22$ \\
$23-24$ \\
Husband's age (years) \\
$15-25$ \\
$26-30$ \\
$31-77$
\end{tabular}

Age at marriage (years)

$$
\begin{aligned}
& <15 \\
& 15-17 \\
& 18-24
\end{aligned}
$$

Educational level

Illiterate

Primary

Secondary

Higher

Religion

Muslim

Non-Muslim

Place of residence

$$
\text { Urban }
$$$$
\text { Rural }
$$

Region

Barisal
Chittagong
Dhaka
Khulna
Rajshahi
Rangpur
Sylhet

Wealth index

$$
\begin{aligned}
& \text { Poorest } \\
& \text { Poorer } \\
& \text { Middle } \\
& \text { Richer }
\end{aligned}
$$

Richest

Husband's occupation Manual

$37.3 \quad 62.7$

$28.9 \quad 71.1$

$26.6 \quad 73.4$

$33.7 \quad 66.3$

$31.3 \quad 68.7$

$29.0 \quad 71.0$

$26.2 \quad 73.8$

$31.8 \quad 68.2$

$39.6 \quad 60.4$

$35.4 \quad 64.6$

$30.5 \quad 69.5$

$31.1 \quad 68.9$

$32.6 \quad 67.4$

$32.0 \quad 68.0$

$25.1 \quad 74.9$

$28.2 \quad 71.8$

$33.1 \quad 66.9$

$\begin{array}{ll}20.9 & 79.1 \\ 42.8 & 57.2 \\ 35.2 & 64.8 \\ 25.0 & 75.0 \\ 25.2 & 74.8 \\ 24.3 & 75.7 \\ 47.7 & 52.3\end{array}$

$29.1 \quad 70.9$

$28.1 \quad 71.9$

$32.8 \quad 67.2$

$33.7 \quad 66.3$

$32.2 \quad 67.8$

Modern p-value
contraceptive
use (\%)
No Yes

$<0.001$

$$
<0.001
$$

$<0.001$

0.011

0.072

$$
0.466
$$

Wants after $2+$ years

Wants, unsure timing

Undecided

Wants no more

Husband's desire for children

Both wanted same

Husband wanted more

0.003

Husband wanted fewer

Did not know

Person who usually decides on respondent's health care

Respondent alone
Respondent and husband jointly
Husband alone
Someone else
Other

Person who usually decides on visits to family or relatives

Respondent alone
Respondent and husband jointly
Husband alone
Someone else
Other

Person who usually decides on large household purchases

$<0.001$

$<0.001$

$\begin{array}{ll}\begin{array}{l}\text { Modern } \\ \text { contraceptive }\end{array} & p \text {-value } \\ \text { use (\%) } & \\ \begin{array}{lll}24.5 \quad 75.5 & \\ 38.1 \quad 61.9 & \\ & & <0.001\end{array}\end{array}$

$24.3 \quad 75.7$

$4.9 \quad 95.1$

$4.8 \quad 95.2$

$34.1 \quad 65.9$

$<0.001$

$61.1 \quad 38.9$

$24.1 \quad 75.9$

$15.5 \quad 84.5$

$19.2 \quad 80.8$

$<0.001$

$76.6 \quad 23.4$

$18.0 \quad 82.0$

$48.1 \quad 51.9$

$47.0 \quad 53.0$

$14.9 \quad 85.1$

$<0.001$

$30.4 \quad 69.6$

$31.9 \quad 68.1$

$26.6 \quad 73.4$

$66.1 \quad 33.9$

$<0.001$

$54.0 \quad 46.0$

$22.7 \quad 77.3$

$28.0 \quad 72.0$

$54.3 \quad 45.7$

$68.8 \quad 31.3$

$<0.001$

0.109

Respondent alone

$52.3 \quad 47.7$

Respondent and husband jointly
$50.3 \quad 49.7$

$23.4 \quad 76.6$

$27.9 \quad 72.1$

$49.6 \quad 50.4$

$57.1 \quad 42.9$

$<0.001$
$24.3 \quad 75.7$ 
Table 1 Percentage distribution of modern contraceptive use by socio-demographic characteristics of women: BDHS 2011 $(n=3507)$ (Continued)

\begin{tabular}{llll}
\hline & $\begin{array}{l}\text { Modern } \\
\text { contraceptive } \\
\text { use (\%) }\end{array}$ & \\
\hline Husband alone & 27.2 & 72.8 & \\
Someone else & 45.9 & 54.1 & \\
Other & 65.0 & 35.0 & \\
Final say on: Child health care & & & $<.001$ \\
Respondent alone & 45.7 & 54.3 \\
Respondent \& husband jointly & 15.5 & 84.5 \\
Husband alone & 20.0 & 80.0 \\
Someone else & 45.8 & 54.2 \\
Other & 60.8 & 39.2 \\
Total & 31.4 & 68.6 & \\
\hline
\end{tabular}

Note: Row percentages sum to $100 \%$; $p$-values are based on chi-square tests

number of children with their husbands' desire. The likelihood of using MC was decreased with increasing age and increased with increasing age at marriage.

\section{Discussion}

This study assessed the relationship between household decision making and $\mathrm{MCU}$ and also identified the other factors contributed to the utilization of $\mathrm{MC}$ among currently married, fecund and non-pregnant women under 25 years old in Bangladesh using Demographic and Health Survey data of 2011.

Results showed that consensus in household decision making regarding women's own health care, visiting family members or relatives and child health care appeared as the third, fourth and sixth most influential contributing factor of $\mathrm{MCU}$, respectively. The most significant factors contributed to using modern contraceptives were desire for children after two years, or want no child at all and receiving FP methods from FP workers. Other key factors that showed significant variability in using $\mathrm{MC}$ were number of living children, husbands engaged in professional non-manual jobs, regional variations and place of residence.

Present study demonstrated that women who were under collective decision-making with their husbands regarding their own health care, child health care and visiting family members or relatives were more likely to use MC than those who took decision alone about these matters. The likelihood of using MC decreased among young women who did not know about their husbands' desires for having children in comparison to women who shared the same feelings regarding parenthood as their husbands. Hence, this study clearly indicated that communication between husband and wife and eventually couples' joint participation in household decision making emerged as one of the most influential factors that might be associated with MCU. Studies suggest that greater gender equality may encourage women's autonomy and may facilitate the uptake of contraception because of increased female participation in decision making [33]. Moreover, male participation in sharing the responsibility to practice and support family planning is identified as a vital strategy in increasing the contraceptive prevalence rate [34].

This study also revealed that women who desired another child after two years go by were more likely to use $\mathrm{MC}$ than those women who desired another child within two years go by. This finding is similar to previous study conducted in Bangladesh, Uganda and Pakistan [35-37]. Some of the reasons for this postponed childbearing as stated in other studies are: women's increased participation on the labour market, including their longer education [38-40] and career planning [38]. Furthermore, financial and practical circumstances during their studies may be difficult to combine with establishing a family, and a high educational level and a desire for career development and will increase the likelihood of delaying child birth in women [40-42]. Young women often express a need to avoid pregnancy because they may be too young to care for a baby, they may have to end or postpone their education [43].

Women who were given family planning methods by the FP workers were more likely to use MC than their counterparts who only talked with the FP workers. Consistently, other studies done in Bangladesh and Cambodia highlighted that outreach activities by FP workers and accessibility to FP related information to married women of reproductive age were significantly associated with use of modern contraceptives [19, 44, 45]. The likelihood of using MC was increased with increasing number of children. This finding is in line with the previous reports from Bangladesh, Tanzania and Pakistan [36, 37, 46].

This study described that women in Sylhet Chittagong, and Dhaka divisions were less likely to use MC than women living in Barisal division. Residing in the rural areas decreased the likelihood of using MC in comparison to their urban counterparts. Studies suggest that geographical variations in the utilization of contraceptives have been found to be influenced by a number of factors like cultural beliefs such as, value attached to child [47], the presence and quality of reproductive health care services [48], the physical characteristics of the area, and the presence of transport routes $[49,50]$.

Women whose husbands did professional jobs were more likely to use MC compared to women whose husbands were manual workers. This study supports findings from several other studies that showed that Muslim women were less likely to use MC than their 
Table 2 Logistic regression model for modern contraceptive use

\begin{tabular}{lll}
\hline Predictors & $\begin{array}{l}\text { Odds Ratio } \\
(95 \% \mathrm{Cl})\end{array}$ & $p$-value \\
\hline
\end{tabular}

Person who usually decides on respondent's health care

Respondent alone ${ }^{\oplus}$

Respondent and husband jointly

Husband alone

$2.761(1.925-3.960)$

Someone else

$2.698(1.875-3.885)$

Other

$1.186(0.770-1.827)$

$2.445(0.577-10.368)$

Final say on: Child health care

Respondent alone ${ }^{\odot}$

Respondent \& husband jointly

$2.616(1.808-3.786)$

Husband alone

$2.164(1.430-3.277)$

Someone else

Other

$1.156(0.739-1.808)$

$1.524(0.982-2.364)$

Person who usually decides on visiting family or relatives

Respondent alone ${ }^{\oplus}$

Respondent and husband jointly

Husband alone

$1.830(1.176-2.849)$

$1.559(0.992-2.449)$

Someone else

$1.377(0.851-2.229)$

Other

$0.876(0.255-3.012)$

Desire for more children

Wants within 2 years ${ }^{\circledR}$

Wants after $2+$ years

Wants, unsure timing

Undecided

Wants no more

14.004 (10.841-18.091)

$5.949(3.032-11.674)$

$3.477(1.902-6.358)$

10.854 (7.517-15.674)

Visited by FP worker in past 6 months

Talked ${ }^{\circledR}$

Gave family planning method

$5.047(2.151-11.840)$

Talked and gave method

No

4.479 (1.228-16.335)

$0.781(0.546-1.117)$

Husband's occupation

Manual ${ }^{\circledR}$

Non-manual

$1.701(1.354-2.138)$

Did not work

$1.264(0.711-2.248)$

Husband's desire for children

Both want same ${ }^{\circledR}$

Husband wants more

Husband wants fewer

Did not know

$0.761(0.522-1.108)$

$1.080(0.734-1.589)$

$0.462(0.281-0.760)$

Religion

Muslim ${ }^{\oplus}$

Non-Muslim

$1.628(1.134-2.336)$

0.008

0.065

0.007

0.054

0.193

0.833

$<0.001$

$<0.001$

$<0.001$

$<0.001$

$<0.001$

$<0.001$

$<0.001$

0.023

0.176

$<0.001$

$<0.001$

0.425

0.010

0.154

0.697

0.002
Table 2 Logistic regression model for modern contraceptive use (Continued)

\begin{tabular}{lll}
\hline Predictors & $\begin{array}{l}\text { Odds Ratio } \\
(95 \% \mathrm{Cl})\end{array}$ & $p$-value \\
\hline $\begin{array}{l}\text { Rural } \\
\text { Region }\end{array}$ & $0.617(0.502-0.759)$ & $<0.001$ \\
$\quad$ Barisal & & $<0.001$ \\
Chittagong & $0.259(0.179-0.375)$ & $<0.001$ \\
Dhaka & $0.479(0.333-0.690)$ & $<0.001$ \\
Khulna & $0.790(0.536-1.166)$ & 0.235 \\
Rajshahi & $0.871(0.585-1.298)$ & 0.498 \\
Rangpur & $0.589(0.396-0.877)$ & 0.009 \\
$\quad$ Sylhet & $0.231(0.150-0.358)$ & $<0.001$ \\
Age & $0.932(0.883-0.984)$ & 0.011 \\
Age at marriage & $1.077(1.018-1.140)$ & 0.010 \\
Number of living children & $1.951(1.516-2.511)$ & $<0.001$ \\
Constant & 0.105 & $<0.001$ \\
\hline Note: $\oplus$ Reference category 6 is confidence interval &
\end{tabular}

Note: ${ }^{\bullet}$ Reference category, $\mathrm{Cl}$ is confidence interval

non-Muslim counterparts [19, 37]. The likelihood of using MC was decreased with increasing age and increased with increasing age at marriage among fecund women aged below 25 years. Therefore, establishment of youth-friendly service centers in convenient places and providing essential materials would encourage young people to use reproductive health services [45].

\section{Limitations}

This study must be considered with some limitations. There may be possibility of threats to internal validity. Firstly, major portions of the observations were dropped (approximately 79\%) during data cleaning because this study considered only currently married, non-pregnant and fecund young women. Therefore, this study would suffer from the selection bias. Secondly, the possibility of under reporting cannot be ruled out since young women may be reluctant to reveal their contraceptive use status. Because, though the government and non-government organizations have a long history of investment in FP, contraceptive use is still a sensitive and often stigmatized subject in Bangladesh [37]. However, the personal interview method applied in this study is widely resorted to for this kind of research.

There may also be a possibility of threat to external validity. Although nationally representative data set was employed, this study cannot be generalized to all women in Bangladesh because it focused on only currently married and fecund young women. Finally, the questionnaire was filled out by the interviewers and their personal opinions might have biased the information. However, according to the BDHS report, interviewers were provided training for implementing the survey based on a training manual

Urban ${ }^{\oplus}$ 
especially developed to enable the field staff to collect data in a friendly, secure, and ethical manner. In spite of these limitations, this study revealed important associations between couples' consensus in decision making and $\mathrm{MCU}$, which have significant implications. Nevertheless, since a nationally representative dataset is used in this study, findings could be a true representation of the situation of this sub-group of women. Moreover, international comparisons of results are possible as DHS surveys take up similar instruments across the countries.

\section{Conclusions}

This study concludes that spousal joint participation in household decision making emerged to be a significant factor contributed to increasing the likelihood of MCU. Therefore, policy makers should focus on developing negotiation skills in young people by creating educational and employment opportunities. Government should include strategic interventions in FP programs to elevate women's status through encouraging more visible involvement in household decision making in order to increase MCU. Besides, desire for a child after two years go by or no child at all contributed the most to increasing the likelihood of MCU, followed by getting FP methods from FP workers. Therefore, this study also suggests that FP interventions should be tailored through wide spreading the activities of FP workers and introducing reproductive and sex education in schools to prepare the young for healthy and responsible living. Because remarkable portions of fecund young women want to either postpone or delay pregnancies but do not use contraceptives, this study suggests a qualitative study to investigate in depth why this sub-group of women does not use contraceptives. In last but not least, contraceptive discontinuation and switching of methods among young and older women would be our future research.

\section{Abbreviations}

BDHS: Bangladesh Demographic and Health Survey; Cl: Confidence Interval; FP: Family planning; MC: Modern contraceptives; MCU: Modern contraceptive use; OR: Odds Ratio

\section{Acknowledgements \\ I would like to acknowledge Dr. Md. Golam Mostofa, Professor, Department of Population Science and Human Resource Development, University of Rajshahi, Bangladesh for his valuable suggestions in carrying out this study. I also acknowledge the MEASURE DHS for providing the data set and all individuals and institutions in Bangladesh involved in the implementation of the BDHS 2011.}

\section{Competing interests}

The author declares that he has no conflict of interests.

\section{Availability of data and materials}

The dataset is available to registered users in http://dhsprogram.com/data/ available-datasets.cfm

\section{Authors' contributions}

The author read and approved the final manuscript.

\section{Ethics approval and consent to participate}

The BDHS data collection procedures were approved by the ORC Macro Institutional Review Board (Calverton, MD, USA). The protocol of the survey was reviewed and approved by the National Ethics Review Committee of the Bangladesh Ministry of Health and Family Welfare. Informed consent was obtained from each of the participants before the interview.

Consent for publication

Not applicable.

\section{Publisher's Note}

Springer Nature remains neutral with regard to jurisdictional claims in published maps and institutional affiliations.

Received: 18 October 2017 Accepted: 15 June 2018

Published online: 22 June 2018

\section{References}

1. Yigzaw M, Zakus D, Tadesse Y, Desalegn M, Fantahun M. Paving the way for universal family planning coverage in Ethiopia: an analysis of wealth related inequality. Int J Equity Health. 2015;14(1):77.

2. Onarheim KH, Taddesse M, Norheim OF, Abdullah M, Miljeteig I. Towards universal health coverage for reproductive health services in Ethiopia: two policy recommendations. Int J Equity Health. 2015;14(1):86.

3. Ahmed S, Li Q, Liu L, Tsui AO. Maternal deaths averted by contraceptive use: an analysis of 172 countries. Lancet. 2012;380(9837):111-25.

4. Liu L, Becker S, Tsui A, Ahmed S. Three methods of estimating births averted nationally by contraception. Popul Stud. 2008;62(2):191-210.

5. Cleland J, Conde-Agudelo A, Peterson H, Ross J, Tsui A. Contraception and health. Lancet. 2012;380(9837):149-56.

6. National Institute of Population Research and Training (NIPORT). Bangladesh demographic and health survey 2014. Mitra and Associates, Dhaka, Bangladesh and ICF International, Calverton, Maryland, USA 2016.

7. Blanc AK. The effect of power in sexual relationships on sexual and reproductive health: an examination of the evidence. Stud Fam Plan. 2001;32(3):189-213.

8. Bawah AA, Akweongo P, Simmons R, Phillips JF. Women's fears and men's anxieties: the impact of family planning on gender relations in northern Ghana. Stud Fam Plan. 1999;30(1):54-66.

9. Do M, Kurimoto N. Women's empowerment and choice of contraceptive methods in selected African countries. Int Perspect Sex Reprod Health. 2012:23-33.

10. Bogale B, Wondafrash M, Tilahun T, Girma E. Married women's decision making power on modern contraceptive use in urban and rural southern Ethiopia. BMC Public Health. 2011;11(1):342.

11. Bourey C, Stephenson R, Bartel D, Rubardt M. Pile sorting innovations: exploring gender norms, power and equity in sub-Saharan Africa. Global public health. 2012;7(9):995-1008.

12. Population Reference Bureau. World population data sheet. In: Population reference bureau Washington; 2015.

13. Central Intelligence Agency. Country comparison to the world. In: The world Factbook; 2015

14. Audu B, Yahya S, Geidam A, Abdussalam H, Takai I, Kyari O. Polygamy and the use of contraceptives. Int J Gynecol Obstet. 2008;101(1):88-92.

15. Ekani-Besala M, Carre N, Calvez T, Thonneau P. Prevalence and determinants of current contraceptive method use in a palm oil company in Cameroon. Contraception. 1998;58:29-34.

16. Oye-Adeniran BA, Adewole IF, Umoh AV, Oladokun A, Gbadegesin A, Ekanem EE. Community-based study of contraceptive behaviour in Nigeria. Afr J Reprod Health. 2006;10(2):90-104.

17. Gakidou E, Vayena E. Use of modern contraception by the poor is falling behind. PLoS Med. 2007;4(2):e31.

18. Islam A, Mondal N, Khatun L, Rahman M, Islam R. Prevalence and determinants of contraceptive use among employed and unemployed women in Bangladesh. International Journal of MCH and AIDS. 2016;5(2):92-102.

19. Rahman M, Islam A, Islam M. Rural-urban differentials of knowledge and practice of contraception in Bangladesh. Journal of Population and Social Studies. 2010;18(2):87-110.

20. Islam AZ, Mostofa MG, Islam MA. Factors affecting unmet need for contraception among currently married fecund young women in Bangladesh. Eur J Contracept Reprod Health Care. 2016:1-6.

21. Islam R, Islam AZ, Rahman M. Unmet need for family planning: experience from urban and rural areas in Bangladesh. Public Health Research. 2013;3(3):37-42. 
22. Cleland J, Bernstein S, Ezeh A, Faundes A, Glasier A, Innis J. Family planning: the unfinished agenda. Lancet. 2006;368(9549):1810-27.

23. Nagase T, Kunii O, Wakai S, Khaleel A. Obstacles to modern contraceptive use among married women in southern urban Maldives. Contraception. 2003;68(2):125-34.

24. Govindasamy P, Malhotra A. Women's position and family planning in Egypt. Stud Fam Plan. 1996:328-40.

25. Rahman M. Women's autonomy and unintended pregnancy among currently pregnant women in Bangladesh. Matern Child Health J. 2012;16(6):1206-14.

26. Haque SE, Rahman M, Mostofa MG, Zahan MS. Reproductive health care utilization among young mothers in Bangladesh: does autonomy matter? Womens Health Issues. 2012;22(2):e171-80.

27. Hindin MJ. Women's autonomy, women's status and fertility-related behavior in Zimbabwe. Popul Res Policy Rev. 2000;19(3):255-82.

28. Allendorf K. Couples' reports of women's autonomy and health-care use in Nepal. Stud Fam Plan. 2007;38(1):35-46.

29. National Institute of Population Research and Training (NIPORT). Bangladesh demographic and health survey 2011. Mitra and Associates, Dhaka, Bangladesh and ICF International, Calverton, Maryland, USA 2013.

30. General Assembly Resolutions, A/RES/62/126 United Nations 2008.

31. Chatterjee S, Hadi AS. Simple linear regression. Regression Analysis by Example, Fourth Edition. 2006:21-51.

32. Chan Y. Biostatistics 202: logistic regression analysis. Singap Med J. 2004; 45(4):149-53.

33. Hakim A, Salway S, Mumtaz Z. Womens autonomy and uptake of contraception in Pakistan. Asia-Pac Popul J. 2003;18(1):63-82.

34. Manaf A, Manaf M. Male participation and sharing of responsibility in strengthening family planning activities in Malaysia Malaysian Journal of Public Health Medicine. 2010; 10(1):23-27.

35. Asiimwe JB, Ndugga P, Mushomi J, Ntozi JPM. Factors associated with modern contraceptive use among young and older women in Uganda; a comparative analysis. BMC Public Health. 2014;14(1):926.

36. Stephenson R, Hennink M. Barriers to family planning service use among the urban poor in Pakistan. Asia-Pac Popul J. 2004;19(2):5-26.

37. Islam AZ, Rahman M, Mostofa MG. Association between contraceptive use and socio-demographic factors of young fecund women in Bangladesh. Sexual \& Reproductive Healthcare. 2017;

38. WHO, UNICEF, UNFPA,the World Bank. Trends in Maternal Mortality: 1990 to 2008. Estimates Developed by WHO, UNICEF, UNFPA and the World Bank. Geneva, Switzerland. 2010.

39. OsayiOsemwenkha S. Gender issues in contraceptive use among educated women in Edo state, Nigeria. African health sciences. 2004;4(1):40-9.

40. Mensch BS, Bruce J, Greene ME. The uncharted passage: girls adolescence in the developing world. New York: Population Council; 1998.

41. Haberland N, Chong E, Bracken H, Parker C. Early marriage and adolescent girls YouthLens on reproductive health and HIV. AIDS. 2005;15:99-119.

42. Chowdhury A, Phillips JF. Predicting contraceptive use in Bangladesh: a logistic regression analysis. J Biosoc Sci. 1989;21(02):161-8.

43. United Nations. Goal 5: improving maternal health. 2012.

44. Thou C. Factors influencing modern contraceptive use among currently married women in Cambodia: Mahidol University; 2008.

45. Islam AZ. Association between modern contraceptive use and sociodemographic factors among fecund young women in Bangladesh. Journal of Women's Health, Issues \& Care. 2017;6(5)

46. Lwelamira J, Mnyamagola G, Msaki M. Knowledge, Attitude and Practice (KAP) towards modern contraceptives among married women of reproductive age in Mpwapwa District, Central Tanzania. Current Research Journal of Social Sciences. 2012;4(3):235-45.

47. Ntozi J. High fertility in rural Uganda. Kampala: Fountain publishers; 1995.

48. Tsui AO, Ochoa LH. The role of family planning programs as a fertility determinant. In: Ross JPJ, editor. Service proximity as a determinant of contraceptive behavior : evidence from cross-National Studies of survey data. London: Oxford University Press; 1992.

49. Nielsen KK, Nielsen SM, Butler R, Lazarus JV. Key barriers to the use of modern contraceptives among women in Albania: a qualitative study. Reproductive health matters. 2012;20(40):158-65.

50. Stephenson R, Baschieri A, Clements S, Hennink M, Madise N. Contextual influences on modern contraceptive use in sub-Saharan Africa. Am J Public Health. 2007;97(7):1233-40.

\section{Ready to submit your research? Choose BMC and benefit from:}

- fast, convenient online submission

- thorough peer review by experienced researchers in your field

- rapid publication on acceptance

- support for research data, including large and complex data types

- gold Open Access which fosters wider collaboration and increased citations

- maximum visibility for your research: over $100 \mathrm{M}$ website views per year

At BMC, research is always in progress.

Learn more biomedcentral.com/submissions 